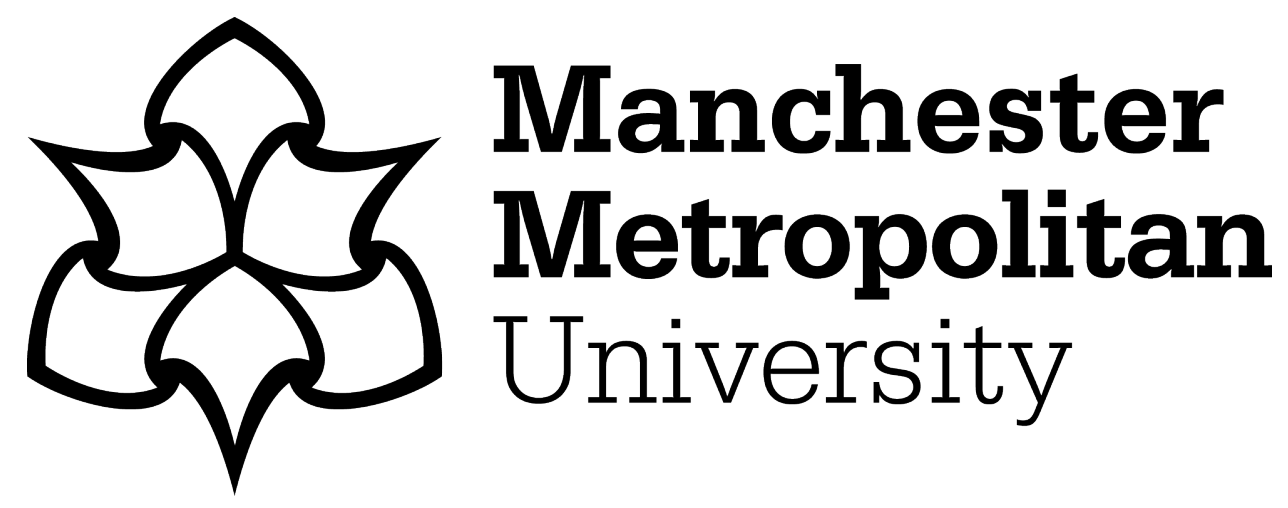

SAVAGE, JONATHAN (2018) Music Education for All. FORUM, 60 (1). p. 111. ISSN 0963-8253

Downloaded from: https://e-space.mmu.ac.uk/621998/

Version: Accepted Version

Publisher: Symposium Books

DOI: https://doi.org/10.15730/forum.2018.60.1.111

Please cite the published version 


\title{
Music Education for All
}

\author{
JONATHAN SAVAGE
}

\begin{abstract}
This article argues that a systematic, developmental and comprehensive music education should be at the heart of every child's formal education within the state education system. The benefits of a music education are briefly explored before a presentation of recent research data that demonstrates a decline in music education as a result of poorly designed and implemented government policies in recent years. Rather than an over-reliance on the 'outsourcing' of music education to music education hubs and other private providers, qualified teachers with appropriate musical and pedagogical skills and understanding hold the key to the provision of a quality music education for all young people. Within primary schools, teachers without a music specialism need to be reminded that music as a subject is not impossible to teach and can be done well with their 'generalist' skills; within secondary schools, music needs to relate to other curriculum subjects in a more explicit way. This is examined through a metaphor drawn from the Renaissance period. Ultimately, this article argues that music education is too important to be left to amateurs. All children deserve a music education that is designed and delivered by qualified and skilful professional educators.
\end{abstract}

\section{Introduction}

It is my contention that music should be a central part of every child's education at school. In making it a core subject within the National Curriculum, the law of the land prescribes that this ought to be the case. Yet, sadly, in many schools today music as a curriculum subject is marginalised for a whole range of reasons. This article will explore several of them. But before I turn to recent research that has explored the situation in our schools today, here is a quick summary of some of the reasons why a systematic, developmental and coherent approach to music education should be available to all our children. 


\section{The Power of Music}

Whatever their age, participating in music making has many benefits for children's academic development, health and well-being. In fact, numerous studies have shown that participating in active music making can be enriching and beneficial at every stage of your life. Practical music making can benefit everyone. It's not just for the talented instrumentalist, amateur songwriter or motivated youngster. At this early stage of life, the benefits of children's engagement with active music making include:

- improvements in perceptual, language, literacy and numeracy skills;

- intellectual development;

- general attainment and creativity;

- personal and social development;

- physical development, health and well-being (Hallam, 2009).

Much of this research focuses on how our brains respond during music-making activities. Neuroscientists have been able to scan the brain and 'map' the various neural centres and pathways that are triggered during certain types of activities. So, making music builds on the brain's functions in specific areas associated with sounds and patterns. These, in turn, are used by the children to learn how to develop spoken and, later, written language (Anvari et al, 2002; Gromko 2005; Daltrozzo \& Schön, 2009).

Other studies have explored how engaging in music making improves general levels of intelligence. For example, Hetland's study (2000) explored the links between musical training and improvements in spatial-temporal reasoning (i.e. the way in which the brain visualises patterns and manipulates them). Folklore tells us that study of music and mathematics are linked. There may be some truth in this. The link between music and spatial intelligence is thought to benefit the sort of thinking required to solve mathematical problems (e.g. being able to recognise and visualise the different elements that work together within a specific mathematical problem). As we know, music is also based around patterns (keys, chord patterns, melodic shapes, etc.); the links become obvious.

So, music is good for our children as individuals. But the benefits extend beyond these into wider school life. Broh's research (2002) showed that participation in music making with others led to significant improvements in our ability to feel part of a community, access a broad range of culture and succeed educationally. Davidson and Good (2002) conducted research that showed how commitment, respect, responsibility and trust were all developed as key skills through regular and structured group music making in young people. At its heart, music making is a social activity. Whether as a young child or a teenager, to play an instrument or sing on your own has many benefits, but why not be proactive about making music together with others as an integral part of a school's daily shared life? Beyond the general benefits, active participation in group music-making activities improves pupils' physical and mental health (Ferguson, 2006) as well as building a stronger sense of community cohesion. 
Returning to our children as individuals for a moment, music making has also been shown to have significant effects on their emotional development and well-being. The physical act of singing can improve mood, increase relaxation and reduce physical and emotional stress (Clift et al, 2008). In a particularly fascinating study, Kreutz (Kreutz et al, 2004) measured the level of cortisol (found in your saliva) in amateur singers both before and after working together in a choir rehearsal. Actively singing together led to increased levels of cortisol (and other chemicals) that promote a positive sense of well-being, increase immune capabilities and enhance one's emotional state. For a vivid example of this, watch the brilliant flash mob song from the West Des Moines Community School District.[1] The joy of song clearly impacted the singers and audience alike.

In addition to the broad benefits that active music making brings to pupils and schools, it is important to remember some of the intrinsic benefits of music making in our lives. Learning to practise, finding the motivation to play well and enjoying the buzz and 'high' of a successful performance all have their own intrinsic benefits. Music forms a vehicle for the development of our own selfexpression and voice. Music brings meaning to our lives. Music, as a unique form of expression and a way of understanding the world, is worthy of being engaged with in and of itself. The true benefits of learning an instrument, writing a song, composing a sonata or listening to a favourite recording artist can never be described adequately in words.

\section{Recent Research into the Current State of Music Education in our Schools}

Research conducted by the University of Sussex in partnership with the Incorporated Society of Musicians (ISM) in 2017 provides us with an insight into the current state of music education in our secondary schools (ISM, 2017). It makes for depressing reading. Researchers received responses from over 700 state schools across England. Responses were from academies and local authority, free and independent schools, with $80 \%$ having an Ofsted grading of 'good' or 'outstanding'. Key findings from the research can be grouped under the headings of Key Stage 3 (KS3), Key Stage 4 (KS4), and Staffing.

\section{Key Stage 3}

Although the number of schools not offering any curriculum time to music was quite small $(2.4 \%)$, the timetabling arrangements for music have shifted with the dramatic curtailment of time for the delivery of music education. Carousel teaching across KS3 (where students only study music for one term in rotation with other subjects) has become more prevalent. This has led to a significant decrease in the time given for music, particularly between the academic year $2015 / 16$ and the year following it $(2016 / 17)$. This saw the average number of hours given for music over the year for Year 8 students drop from 20.8 hours to 
17.5 hours. The least time offered for music via a carousel approach was 25 minutes for six weeks in the year. This equates to just 2.5 hours across the entire academic year.

An increasing number of schools have made music optional in Year 9, despite the subject being in the National Curriculum. In 2012/13, music was compulsory for all Year 9 students in $84 \%$ of schools. By 2015/16 this percentage had dropped to $67 \%$. In $2016 / 17$ it decreased still further to $62 \%$. It should also be noted that in many schools, students now begin to undertake GCSE studies in Year 9, rather than in Year 10 (see below). This results in a complete cessation of all subjects that fall outside the student's particular GCSE choices. Adherence to the principle of a 'broad and balanced' curriculum in these schools would seem to be questionable!

\section{Key Stage 4}

At KS4, the consequences of the imposition of the English Baccalaureate (EBacc) have had a hugely detrimental impact on music education (and on other subjects that fall outside the EBacc prescription): $59.7 \%$ (393) of the researched schools highlighted the EBacc specifically as having a negative impact on the provision and uptake of music in their school (within and beyond the curriculum). Conversely, just $3 \%$ considered that the EBacc had a positive impact on music.

The number of schools offering GCSE Music at the start of the 2016/17 academic year was $79 \%$ (down from $85 \%$ in 2012/13). Students in these schools do not have an opportunity to take a GCSE in music at all. The number of students taking music qualifications other than GCSE has also reduced. For example, there is a 70\% reduction in schools offering a Business and Technology Education Council (BTEC) qualification at Level 2, from 166 schools in 2012/13 to 50 schools in 2016/17.

Eighteen per cent of schools reported that not every pupil was able to opt for music as an examination subject at KS4 should they wish to do so. Evidence from the data shows that the EBacc has a detrimental impact on whether students are able to opt for music where it is offered.

Of those schools offering GCSE Music, $11 \%$ taught the course out of core curriculum time. It is hard to think of any other subjects where this would be considered an acceptable approach. Yet music teachers in these schools are caught between a rock and a hard place if they want to facilitate music education for students through these courses.

As the researchers made clear, it is also important to note that GCSE uptake figures for 2016/17 will have been artificially boosted where schools have changed to a three-year KS4 (i.e. starting in Year 9) as these figures will include two different year groups starting the qualification in the same year.

Teachers felt the two most common reasons that impacted negatively on students choosing music at KS4 were the EBacc (57.3\%), and changes in 
options available to students when they selected their GCSE subjects (25.1\%). As these two are frequently interlinked, this gives a combined total of $82.4 \%$.[2]

Other changes the researchers identified that impacted negatively on the provision of music education at KS4 were: booster classes (36\%); shortened lunchtimes (31\%); and fewer extracurricular opportunities (12\%).

\section{Staffing Changes}

Finally, the researchers examined the changes in staffing levels for music education in these schools. They found that the average number of full-time equivalent music staff is reducing year on year: $39 \%$ of respondents reported falling staffing levels for music departments, with only $17 \%$ indicating levels had risen. Specifically, the number of music departments staffed by a single teacher was up from $22 \%$ in $2012 / 13$ to $30 \%$ in $2016 / 17$. This is a concern in terms of the potential for further isolation of music teachers. There is also less capacity in the place should secondary numbers continue to rise.

Despite the government's stated aim for music education hubs (i.e. groups of organisations such as education authorities and voluntary groups combining to offer music education) to play an integral part in the music education on offer for our children, it is my contention that schools are best placed to offer a systematic, developmental and coherent music education to their students. While music education hubs have a role to play in offering specialist instrumental tuition, their services should not be seen as supplanting the delivery of music as a core curriculum subject as part of a broad and balanced curriculum. Yet, sadly, this is often the case, particularly in primary schools across England. Here, partly due to cuts in the time and resources dedicated to initial teacher education programmes, teachers often feel under-prepared to teach music, which, they argue, is something that requires specific skills, knowledge and understanding that they do not possess. I'll address this further below.

\section{Qualified Teachers Matter}

For now, it is my strong contention that every teacher teaching within our schools should be qualified. What does that mean? Traditionally, this has meant that all teachers in the maintained sector should have, as a minimum level of qualification, an undergraduate degree and qualified teacher status (QTS). Sadly, both these elements have been removed in many schools by this government's recent educational policies.

QTS can be obtained in various ways. The majority of would-be teachers obtain it through studying for a PGCE (a postgraduate-level qualification that is not the same as QTS, being an academic award in its own right offered to students by universities and not the government). The award of a PGCE, and as part of this, QTS, offers would-be music teachers many essential skills. Here's is a list of some of the things that it teaches student teachers: 
- the ability to plan for musical learning in individual lessons and sequences of lessons in such a way that learning is initiated, sustained and developed;

- the knowledge to choose and use a range of different teaching resources effectively;

- the techniques of differentiation and personalisation, where musical learning is tailored to the individual needs of students;

- the ability to assess students' work, formatively and summatively, so that key musical learning can be identified and evaluated and students can maximise their progress;

- the constructive use of accountability and reporting mechanisms so that the school, parents and others can be assured that music teaching is of a high quality and learning is progressing well in the classroom;

- skilful approaches to communication with students, including the ability to explain things clearly, model key musical processes and question students about their work and promote their thinking;

- the management of student behaviour through positive reinforcement techniques rather than negative approaches;

- an introduction to the wider theories of educational and developmental psychology that underpin all teaching and learning in music;

- the notion of teacher identity, how it is developed and formed over time, and how it relates to important precursors (i.e. your own identity pre-teaching) and broader discourses around music as a discrete subject with its own history, priorities and culture;

- an important challenge to the powerful but potentially fatal influence of teaching in the way that you might yourself have been taught. QTS develops the central notion of the reflective teacher/practitioner, which is an essential attribute if you are to learn to teach well in the classroom;

- linked to this, the ability to evaluate teaching and learning using specific tools and make changes to your curriculum at key points;

- detailed knowledge of National Curriculum, exam specifications and the like that frame the work of teachers.

For all these reasons, my belief is that every teacher teaching music in primary and secondary school should have an undergraduate degree, a PGCE and QTS. Anything less than that is selling our children short.

This government has a different view. It feels that teaching is not something that needs this level of qualification. It has set about to systematically destroy the basis of such teacher qualification and thereby to give academies and free schools the same 'freedoms' that the independent schools have 'enjoyed' for many years. But I don't want my children educated in an independent school or through a system that adopts the practices of that sector either. As we have seen recently, allowing maintained schools to employ unqualified teachers is a recipe for disaster. A music education for every child is too precious to be compromised by well-meaning and misguided amateur teachers. 
That said, many qualified teachers in primary school often express concerns about the teaching of music, seeing it as a difficult subject in which they lack skills. I would argue that this is often not the case and that these teachers are far more skilled than they might realise. The metaphorical story of the fox and the hedgehog illustrates this point well. Following on from a fragment attributed to Archilochus in $650 \mathrm{BC}$, that 'the fox knows many things, but the hedgehog knows one big thing', Isaiah Berlin wrote:

For there exists a great chasm between those, on one side, who relate everything to a single central vision, one system, less or more coherent or articulate, in terms of which they understand, think and feel - a single, universal, organising principle in terms of which alone all that they are and say has significance - and, on the other side, those who pursue many ends, often unrelated and even contradictory, connected, if at all, only in some de facto way, for some psychological or physiological cause, related to no moral or aesthetic principle. These last lead lives, perform acts and entertain ideas that are centrifugal rather than centripetal; their thought is scattered or diffused, moving on many levels, seizing upon the essence of a vast variety of experiences and objects for what they are in themselves, without, consciously or unconsciously, seeking to fit them into, or exclude them from, any one unchanging, allembracing, sometimes self-contradictory and incomplete, at times fanatical, unitary inner vision. The first kind of intellectual and artistic personality belongs to the hedgehogs, the second to the foxes. (Berlin, 1953, pp. 1-2)

So, put simply, Berlin's application of Archilochus is that humans can be categorised as being either hedgehogs or foxes. Hedgehogs' lives are dominated by a single, central vision of reality through which they think and feel. Foxes, in contrast, live what might be called a centrifugal life, pursuing many divergent ends.

For me, the potential strengths of the generalist teacher of music (the fox) outweigh the potential benefits of the specialist music teacher (the hedgehog) within the primary school. Janet Mills, ex-Chief HMI for Music, was a strong advocate of this approach. This is outlined in her book Music and the School:

Some of the finest music teachers that I have observed, particularly, but not only, in primary schools, have no qualifications in music, and teach many subjects - in some cases the whole of the primary curriculum. They may never have learned to play an instrument, and they may not have read staff notation well, or at all. What they bring to their music teaching is their ability, typically developed in other subjects, to diagnose where students are, and work out ways of helping them to learn, frequently coupled with a degree of humility about their music skills that leaves them continually questioning how well their students are learning, and whether there are 
approaches that would enable them to learn more rapidly. They also often bring particular musical skills, interests, and knowledge that are additional to those of the teacher in charge of music at the school, and that enrich the music curriculum of the school.

When teachers with little formal training in music teach it, their problem is often confidence, rather than competence. When I work as an inspector in schools, such teachers sometimes try to apologize to me for their teaching before they have even begun, and then the most wonderful lesson unfolds as they focus on the students, closely observe what the students can do and what they cannot do yet, and use a range of skills developed in other subjects to help the students make progress. (Mills, 2005, pp. 28-29)

As generalists, primary teachers are in an ideal place to teach music well. They should be more confident and should not separate the teaching of music from their wider skills as teachers. In the secondary school, there is a much stronger argument for subject specialists in music and all other National Curriculum subjects. But even there, the boundaries between subjects, their teaching in 'specialist' facilities, and the rigid timetabling approaches that dominate these schools can all be tremendously unhelpful in facilitating a holistic approach to curriculum development.

In my book arguing for a cross-curricular approach to curriculum development in the secondary school (Savage, 2011), I used a metaphor drawn from Renaissance music to help illustrate this point. Renaissance music is often characterised as being polyphonic (literally, 'many sounds'), as opposed to monophonic (literally, 'one sound') as found in medieval plainchant. As the Renaissance period merged into the Baroque (around 1750), polyphonic musical textures transformed into homophonic (i.e. having the same sound), which resulted in a melodic line being supported by a chordal accompaniment (i.e. the melodic line became of primary importance, with the bass line and chordal parts supporting it). In contrast, the art of writing polyphonic music centred on the composer's ability to write for many voices as if they were one. Composers tried to do this by:

- sharing common melodic materials between the voices;

- allowing different voices to take the lead at different times;

- ensuring that the voices were equally important and that one voice did not dominate the music at any given point;

- handling dissonance (i.e. what could be perceived as 'clashes' in the sound of the music at a particular point) in a specific way, making sure that any of these tensions in the music were both prepared and resolved for the listener.

Renaissance polyphonic music expressed the metaphors of universal orderliness and interdependence within a perfect musical form. The result of this approach was the most beautiful religious music, characterised by its many interweaving 
parts sounding as one which can be heard, daily, in cathedrals and other large churches to this day.

For our Renaissance curriculum model, this type of subject polyphony would be something to aspire to. It would permeate our Renaissance curriculum model by allowing key knowledge, skills and understanding which are initiated by individual subjects (voices) to be shared across subjects (between voices) in a way that allows them to exist alongside each other with an equal sense of value. It could allow particular subjects to take the lead at particular times, but always within a combined, overall sense of balance, purpose and direction. It could highlight a specific theme for a certain period, sharing it among subjects and allowing each to present it with its own particular subject tone or resonance. It could handle potential clashes of knowledge or learning by carefully preparing learners for the potential dissonance, allowing them to enjoy the creative tension that the dissonance allows before resolving it for them in a sensitively managed and appropriate way.

In their 5 April 2011 statement entitled 'The Value of Music: the right to play', the Fellows of the Salzburg Global Seminar asserted that music is a proven gateway to engaged citizenship, personal development and well-being. The benefits of a music education are universal, they argued, and must be available to all as a human right. They argued that:

All children from the earliest age should have the opportunity to:

- Unlock musical creativity;

- Fulfil musical potential;

- Develop musical expertise;

- Shine for their musical achievements;

- Encounter great music from all cultures; and

- Share their new-found skills of creativity, teamwork, empathy, and discipline.

Providing these opportunities should be the responsibility of society supported by the education system, arts organisations, media and funding bodies working together. (Salzburg Global Seminar, 2011)

Schools are in the best place to fulfil these lofty aims. All teachers need to be well educated and skilful in terms of the application of their subject and their pedagogical knowledge. Clearly, there may be good and bad qualified music teachers just as there are good and bad unqualified music teachers. But building an educational system across England that removes the need for vast swathes of schools to employ qualified teachers is a stupid policy that will seriously undermine the educational and musical opportunities of the children at these schools. Our children deserve better.

\section{Notes}

[1] https://www.youtube.com/watch?v=cGMlPDIY094

[2] Based on 604 responses, both positive and negative. 


\section{References}

Anvari, S.H., Trainor, L.J., Woodside, J. \& Levy, B.A. (2002) Relations among Musical Skills, Phonological Processing, and Early Reading Ability in Preschool Children, Journal of Experimental Child Psychology, 83(2), 111-130. https://doi.org/10.1016/S0022-0965(02)00124-8

Berlin, I. (1953) The Hedgehog and the Fox: an essay on Tolstoy's view of history. London: Weidenfeld \& Nicolson.

Broh, B. (2002) Linking Extracurricular Programming to Academic Achievement: who benefits and why? Sociology of Education, 75(1), 69-95. https://doi.org/10.2307/3090254

Clift, S., Hancox, G., Staricoff, R. \& Whitmore, C. (2008) A Systematic Mapping and Review of Non-clinical Research on Singing and Health. Canterbury: Sidney De Haan Research Centre for Arts and Health, Canterbury Christ Church University.

Daltrozzo, J. \& Schön, D. (2009) Conceptual Processing in Music as Revealed by N400 Effects on Words and Musical Targets, Journal of Cognitive Neuroscience, 21(10): 1882-1892. https://doi.org/10.1162/jocn.2009.21113

Davidson, J. \& Good, J. (2002) Social and Musical Co-ordination between Members of a String Quartet: an exploratory study, Psychology of Music, 30(2), 186. https://doi.org/10.1177/0305735602302005

Ferguson, K. (2006) Social Capital and Children's Wellbeing: a critical synthesis of the international social capital literature, International Journal of Social Welfare, 15(1), 2. https://doi.org/10.1111/j.1468-2397.2006.00575.x

Gromko, J.E. (2005) The Effect of Music Instruction on Phonemic Awareness in Beginning Readers, Journal of Research in Music Education, 53(3), 199-209. https://doi.org/10.1177/002242940505300302

Hallam, S. (2009) The Power of Music. London: Youth Music.

Hetland, L. (2000) Learning to Make Music Enhances Spatial Reasoning, Journal of Aesthetic Education, 179-238. https://doi.org/10.2307/3333643

Incorporated Society of Musicians (ISM) (2017) Changes in Secondary Music Curriculum Provision Over Time 2012-16. https://www.ism.org/news/changesin-secondary-music-curriculum-provision-over-time-2012-16 (accessed 4 November 2017).

Kreutz, G., Bongard, S., Rohrmann, S., Hodapp, V. \& Grebe, D. (2004). Effects of Choir Singing or Listening on Secretory Immunoglobulin A, Cortisol, and Emotional State, Journal of Behavioral Medicine, 27(6), 623-635. https://doi.org/10.1007/s10865-004-0006-9

Mills, J. (2005) Music in the School. Oxford: Oxford University Press.

Salzburg Global Seminar (2011) The Value of Music: the right to play. http://www.salzburgglobal.org/calendar/2010-2019/2011/session-479.html (accessed 15 November 2017).

Savage, J. (2011) Cross Curricular Teaching and Learning in the Secondary School. London: Routledge. 
Dr JONATHAN SAVAGE is a Reader in Education at the Faculty of Education, Manchester Metropolitan University. He is managing director of UCan Play, a not-for-profit company that runs consultancy, research and training as well as providing a point of sale for musical instruments and audio and video technologies. He is a widely published author, having written 16 books for Routledge, the Open University Press and SAGE, together with numerous academic papers. Jonathan runs an active blog at www.ucanplay.org.uk and can be followed on Twitter@jpjsavage. Correspondence: j.savage@mmu.ac.uk 
